\title{
O projeto da Escola de Serviço Social de Belo Horizonte - 1960-1975:
} uma reconstrução histórica

The project of the School of Belo Horizonte's Social Work - 1960-1975: a historical reconstruction

\author{
Maria Rosângela Batistoni ${ }^{a}$ \\ (1) https://orcid.org/0000-0002-6859-8243
}

\begin{abstract}
Resumo: Este artigo apresenta alguns dos caminhos e "achados" investigativos de uma pesquisa de reconstrução histórica do projeto da Escola de Serviço Social da Universidade Católica de Minas Gerais. Destaca suas bases sociopolíticas, as concepções teórico-metodológicas norteadoras da proposta, seus vínculos com as forças contestadoras da profissão nos países do continente latino-americano, influências e desdobramentos para o Serviço Social.

Palavras-chave: Movimento de Reconceituação no Brasil. "Método Belo Horizonte". Marxismos.
\end{abstract}

\begin{abstract}
This article presents the investigative paths and findings of a historical reconstruction research about the project of the Social Work School of the Catholic University in Minas Gerais. It emphasizes its socio-political bases, the theoretical-methodological conceptions guiding its proposal, its links with the challenging forces of the profession in Latin American countries and its influences and unfoldings for social work
\end{abstract}

Keywords: Reconceptualization Movement in Brazil. "Belo Horizonte Method". Marxisms.

aUniversidade Federal de São Paulo/Unifesp — Baixada Santista, Santos/SP, Brasil.

Recebido: 26/5/2019 - Aprovado: 30/5/2019 
Os tempos mudavam, no devagar, depressa dos tempos.

Guimarães Rosa

\section{Introdução}

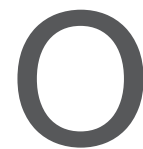

projeto da Escola de Serviço Social da Universidade Católica de Minas Gerais emergiu na primeira metade dos anos 1970, sob a ditadura empresarial militar no país, ${ }^{2}$ tornando-se um núcleo de oposição e contestação, sob os influxos das mudanças acadêmico-profissionais do Movimento de Reconceituação, tal como nos países de língua hispânica da América Latina. ${ }^{3}$ Formulou uma alternativa global ao tradicionalismo, o inicial e abrangente momento da perspectiva renovadora de intenção de ruptura no Brasil, como qualifica Netto (1991, p. 276-277; grifos no original):

O "método" que ali se elaborou foi além da crítica ideológica, da denúncia epistemológica e metodológica e da recusa de práticas próprias do tradicionalismo, envolvendo todos estes passos, ele coroou a sua ultrapassagem no desenho de um inteiro projeto profissional abrangente, oferecendo uma pauta paradigmática dedicada a dar conta inclusive de um conjunto de suportes acadêmicos para a formação de quadros técnicos e para a intervenção do Serviço Social.

Os processos e condicionantes político-institucionais da ditadura inviabilizaram a ressonância e difusão do projeto da escola mineira

1 Este estudo é parte de pós-doutorado da autora junto ao Programa de Pós-Graduação em Serviço Social da Uerj; integra a pesquisa coletiva em rede internacional "O Movimento de Reconceituação do Serviço Social na América Latina (Argentina, Brasil, Chile e Colômbia): determinantes históricos, interlocuções internacionais e memória (1960-1980)", sob a coordenação das pesquisadoras profas. dras. Marilda V. Iamamoto (Uerj) e Cláudia M. dos Santos (UFJF).

2 Sobre o tema, há vasta bibliografia. Aqui recorre-se a Fernandes (1976), Ianni (1981), Netto (1991 e 2014).

3 Sobre o movimento de reconceituação, ver Alayón (2005), Iamamoto (1980 e 2015) e Netto (1991, 1981 e 2005). 
junto a outras unidades de ensino e organismos da categoria no país, permanecendo isolada até o fim da década. Ressalte-se que o isolamento da experiência belo-horizontina é acrescido pelo fato de que no meio acadêmico-profissional a reconceituação assumiu a perspectiva hegemônica de uma modernização conservadora e tecnocrática, expressa nas sistematizações teóricas dos documentos de Araxá (1967) e de Teresópolis (1970) conduzidas pelo CBCISS (Centro Brasileiro de Cooperação e Intercâmbio de Serviços Sociais) com traços de funcionalidade ao regime autocrático, demarcando projetos em oposição na tensa disputa teórica e ideológica pela hegemonia na renovação do Serviço Social brasileiro.

No entanto, as formulações Escola de Serviço Social da UCMG ganharam ampla visibilidade nas universidades latino-americanas, afirmando-se como uma de suas referências exemplares, dada a sintonia com a feição crítica da reconceituação e os vínculos com as forças contestadoras da profissão na América Latina. A proposta reconceituadora da escola foi interrompida em 1975, em meio a uma crise interna, no processo contraditório de uma greve estudantil, gerando o pedido de demissão de todo corpo docente, acatado pelas instâncias superiores de UCMG, inclusive sua equipe formuladora e dirigente, inviabilizando sua continuidade naquele momento e espaço. Paradoxalmente, seu desfecho ocorreu no momento em que se abria a crise da ditadura militar e as primeiras manifestações abertas de resistência e oposição se enunciavam. O resgate do projeto da escola reapareceu para segmentos do Serviço Social brasileiro no final da década de 1970 e início da seguinte, sob novas bases sociais e políticas do país, com a reinserção do movimento das classes trabalhadoras na cena histórica.

Deve-se ressaltar que a perspectiva orientadora desta análise é de uma crítica que se autoimplica, que se defronta com o objeto para transformá-lo e negá-lo, transformando-se ao mesmo tempo. Portanto, esta análise inscreve-se no esforço coletivo e desafiador "na contribuição à tarefa inconclusa para o adensamento dos fundamentos históricos e teóricos da profissão" (2017, p. 147). 


\section{Caminhos e "achados" investigativos}

A construção dos eixos e das diretrizes do trabalho investigativo deste estudo sintoniza-se com os próprios eixos e diretrizes definidos na pesquisa coletiva da rede internacional à qual se vincula, ao mesmo tempo em que atenta para os processos reais particulares do projeto da ESS/ UCMG, revelando novos achados, outras ênfases ou reafirmando análises já formuladas que, no limite deste artigo, são apenas sinalizadas. Segue uma exposição sucinta da necessária pesquisa histórica e da interlocução teórico-metodológica crítica com o conhecimento acumulado que o estudo implicou, enquanto também revela as particularidades constitutivas do projeto daquela escola no interior do movimento de reconceituação. ${ }^{4}$

\subsection{Antecedentes e as bases sociopolíticas do projeto da ESS/UCMG}

A experiência da Escola de Serviço Social mineira emergiu na primeira metade dos anos 1970, logo após o Ato Institucional n. 5 (AI-5) da ditadura civil-militar, contexto em que a repressão e a violência policial militar institucionalizaram-se em todo seu alcance nos poros do Estado, estendendo-se para a sociedade civil. O regime político civil-militar compeliu as forças sociais e políticas democráticas e da esquerda sobreviventes, ao isolamento, à prática de resistência fragmentada, clandestina, residual e molecular. Livre de qualquer contestação, a ditadura militar

\footnotetext{
4 As fontes sobre a experiência da escola mineira - documentos elaborados entre 1971 e 1976 — são de difícil localização. Em geral foram publicados em compêndios por editoras vinculadas à reconceituação nos países de língua hispânica, como Quiroga (Org.) (1973 a e 1973b). Outros, resgatados nos raros estudos sobre o projeto da Escola, estão em Lima Santos (1982), Netto (1991), Barbosa (1989) e Portella (1992). Portella (1992. p. 10-110 registra com indignação a comprovação de que nos arquivos da Escola, quando de sua pesquisa em 1992, não foi localizado material que documenta o período de 1972 a 1975. Há inúmeros registros e documentos importantes referentes à proposta pedagógica em arquivo pessoal de uma ex-docente, no momento em processo de organização.
} 
garantiu as condições sob as quais o grande capital monopolista, nacional e estrangeiro, alcançou as mais altas taxas de lucros, "uma espécie de mais-valia extraordinária”, com a superexploração dos trabalhadores, nos termos de Ianni (1981, p. 79).

Na compreensão dos antecedentes e das bases sociopolíticas da ESS/ UCMG situa-se a dinâmica da política e da cultura no período de 1964 a 1968, no qual, passada a violenta repressão que se seguiu ao golpe, as lideranças democráticas comprometidas com as forças populares e de esquerda buscaram estratégias de rearticulação para confrontar o regime. Ao mesmo tempo, o "modelo econômico", assentado no fim da estabilidade do emprego e com uma política salarial depressiva (o arrocho salarial), atingiu os trabalhadores em suas condições imediatas de trabalho e de vida, desdobrando-se ainda em insatisfação na pequena burguesia urbana, que teve no movimento estudantil universitário sua manifestação mais visível.

A inquietude e a explosão contestatória evidenciaram o florescimento de uma cultura predominantemente de esquerda, em todas as suas expressões (na literatura, no cinema, na música, na emergência de movimentos culturais), repercutindo na particularidade da conjuntura nacional os processos dos países capitalistas centrais e da periferia latino-americana (Ridenti, 2010; Netto, 2014).

Minas Gerais foi campo político das elites reacionárias articuladoras do golpe de 1964, como analisa Starling (1986), mas, na contratendência, a região metropolitana de Belo Horizonte, em ampla industrialização e modernização desde meados dos anos de 1950, foi cenário de importantes movimentos populares e sindicais (Neves,1995) e com uma forte tradição estudantil - democrática e de perspectivas revolucionárias e socialistas. ${ }^{5}$ A vinculação dessa militância à experiência da ESS/UCMG

5 Destaca-se o protagonismo da chamada esquerda católica, através da Juventude Universitária Católica - JUC, base para o surgimento da organização Ação Popular - AP, bem como de integrantes do Partido Comunista do Brasil — PCdoB e também da Organização Revolucionária Marxista Política Operária - ORM-Polop. 
foi expressiva e cunhou marcas em seu projeto. Em 1968 deu-se a eclosão da greve operária de Contagem, no cinturão industrial da capital, ${ }^{6}$ a primeira depois do golpe, em aberto confronto tanto com a ditadura que cerceava a liberdade e a autonomia sindical, quanto com a política econômica fundada na superexploração do trabalho que, reivindicando aumento salarial acima dos índices oficiais, surpreenderam o governo militar, que foi obrigado a ceder (2014). O movimento grevista contou com o apoio e a solidariedade de estudantes, intelectuais, quadros da Igreja católica, além da ação dos grupos da esquerda.

Essa dinâmica sociopolítica conjugou "para tornar Belo Horizonte um tópos adequado à expressão inicial do projeto profissional da ruptura" (Netto, 1991, p. 262). Articula-se àquelas referências o fato de a experiência da escola mineira desenvolver-se em uma instituição universitária com condições relativamente favoráveis pela presença de forças progressistas da hierarquia católica, oferecendo, aos docentes e discentes, espaço de resistência intelectual e política. O estudo inédito de Portella (1992) busca desvendar a participação e afinidades entre diferentes atores vinculados a instituições que têm fins inter-relacionados, ou seja, a Igreja católica em Minas, particularmente sob a autocracia burguesa, as bases ideopolíticas da Universidade Católica de Minas Gerais, desdobrando-se no movimento universitário católico (em especial da JUC), e a trajetória histórica da Escola de Serviço Social de Belo Horizonte (de 1946 até o desfecho da proposta reconceituada em 1975), estabelecendo os nexos de confluências e alianças, embates e rupturas entre esses agentes.

Esse constitui outro eixo na apreensão dos antecedentes e condutos perseguidos em nosso estudo, mas, no limite deste artigo, restringe-se

6 Repercutiam ainda as lutas operárias nas siderúrgicas localizadas no quadrilátero ferrífero mineiro, região de maior produção nacional de minério de ferro, como a greve dos operários da Siderúrgica Usiminas em Ipatinga em 1963, que, pela ação da polícia militar, levou a oito trabalhadores assassinados e 78 feridos, fato conhecido como Massacre de Ipatinga, mas obscurecido pela lei do silêncio (Fernandes, 2013). Deve-se ressaltar que a cidade de Itabira (onde se localiza a Companhia Vale do Rio Doce), com a presença das ações pastorais progressistas da Igreja católica, foi o locus principal de experimentação do método BH. 
aos marcos principais da trajetória da ESS/UCMG, suas origens (1946) e ulterior desenvolvimento se assemelham às que lhe precederam no país, seja quanto aos condicionantes históricos conjunturais, seja quanto às concepções, conteúdos doutrinários emanados do ideário católico num arranjo com as referências funcionalistas das influências do Serviço Social clássico norte-americano no processo formativo. Sua incorporação à UC ocorreu em 1954, demarcando também sua vinculação às práticas de desenvolvimento e organização de comunidade, acompanhando as diretrizes da Igreja católica e do Estado no âmbito da política desenvolvimentista, com ênfase no Serviço Social rural em regiões agrárias do estado mineiro. A partir de 1961, a Escola busca sua modernização pelo influxo da interlocução com as ciências sociais e humanas no currículo pela renovação do quadro docente, mediante a preparação das alunas que se destacavam no ensino e nos estágios, conforme depoimentos recolhidos por Portella (1992). ${ }^{7}$ No entanto, a linha de força nesse processo advém, sobretudo, do movimento estudantil, com parcela de discentes dos quadros da JUC, da Ação Popular e da Polop que, além da politização dos processos educacionais, trazia as experiências do trabalho de comunidade, educação e cultura popular. Desse modo, a Escola passou a encampar como atividade curricular as práticas vinculadas ao Movimento de Educação de Base - MEB, impondo-se o estudo da pedagogia de Paulo Freire, antecedentes relevantes na formulação do projeto reconceituador (cf. ESS/UCMG,1974). Como se conhece, essas foram práticas profissionais vetoras dos primeiros questionamentos às bases tradicionais do Serviço Social, apontando a possibilidade de vinculá-lo a projetos pertinentes aos interesses das classes trabalhadoras, processo este que Netto (1991, p. 136-142) analisou como a erosão

\footnotetext{
Deve-se lembrar que no âmbito das universidades, evidenciou-se uma aberta politização sintonizada com as lutas sociais e a democratização em curso, destacando-se a luta em defesa da escola pública e o debate da Lei de Diretrizes e Bases da Educação de 1961. A radicalização à esquerda também se efetivou nas ciências sociais, beneficiando-se da interlocução com autores marxistas, mas não só, bem como na definição do seu papel face à realidade subdesenvolvida e dependente da América Latina.
} 
do Serviço Social tradicional no Brasil, interrompido com a instauração da ditadura empresarial militar.

No imediato pós-golpe, o regime atinge diretamente as universidades e instituições, realizando o controle e a destruição das organizações de docentes, pesquisadores estudantes, bem como de experiências e alternativas destinadas a democratizar os sistemas e processos educacionais, vinculando-as às necessidades da massa da população. No entanto, entre 1964 e 1968, o sistema educacional e universitário constituía um dos flancos vulneráveis e abertos ao apelo político contra a ditadura militar. Só a partir de 1968-9 o regime autocrático golpeia o conjunto das instituições do sistema educacional, instaurando uma política de educação compatível com o conjunto da política social da ditadura, funcional ao "modelo econômico", iniciando pelas universidades, associadas a outras medidas de forte repressão. ${ }^{8}$

Na ESS/UCMG os impactos das mudanças impostas podem ser analisadas sob dois ângulos. De um lado, a vigência de confrontos diretos com a repressão militar, com perseguições e prisões de alunos e professores, invasão e fechamento da Escola pelos militares logo após o golpe, abertura de IPMs, processos do Decreto n. 477, silenciamentos e medo. Essa situação perdurou até o final da década seguinte, como expressam os depoimentos coletados por Silva (1991), Portella (1992) e ainda em publicação do CFESS (2017) e pela Comissão da Verdade (2017). E de outro, a meta de "promover e consolidar o projeto profissional modernizador, compatível e funcional ao projeto da autocracia burguesa" (Portella, 1992, p. 223), acompanhando a tendência predominante da formação em Serviço Social brasileiro. As diretrizes formuladas no Seminário de Araxá em 1967 rebateram diretamente na estrutura curricular do curso, pelo caráter dinâmico e reformista da sua direção e vinculação com o CBCISS. Dessa mudança decorreu a retração dos campos de estágio em

8 Situa-se nessa ofensiva o Decreto-lei n. 477, de 1969, conhecido como o AI-5 do sistema educacional. Sobre a política educacional da ditadura, cito Góes e Cunha (1985), Fernandes (1979), Netto (1991) e Mota (2014). 
comunidades e sua ampliação em instituições públicas de política social, em especial na política habitacional, que se tornou um espaço inusitado de estágio acadêmico e atuação profissional. A escola respondeu a essa nova demanda, reconduzindo para os campos de habitação popular, alunos remanescentes das práticas no MEB e de outras experiências em comunidade, como assinala a autora supracitada. Esse processo ainda carece de melhor análise, pois a área da habitação e moradia demandava uma modalidade de atuação de grande funcionalidade para o regime. No entanto, configurou-se como escoadouro das tensões sociais de parcelas da classe trabalhadora e para o qual convergiram assistentes sociais para atuar numa atividade comunitária peculiar, consolidando-se dez anos depois, em Minas, em seguida, Rio e São Paulo, nas experiências dos Inocoops. Deve-se destacar que, simultaneamente, esse espaço foi nucleador de algumas das principais lideranças e protagonistas da reorganização sindical da categoria profissional nos três estados, cuja manifestação pública contestadora de oposição à ditadura se deu por ocasião do III ${ }^{\circ}$ Congresso Brasileiro de Assistentes Sociais, no emblemático e denominado "Congresso da Virada" em São Paulo em 1979, no mesmo momento das massivas greves do operariado metalúrgico na capital e no ABC paulista. Sob inspiração da análise provocadora de Iasi (2016), pode-se se afirmar que, naquela dinâmica, os fios históricos da ação coletiva se conectaram, formando as bases subjetivas de um tempo no qual segmentos profissionais selaram os rumos do Serviço Social brasileiro aos destinos do conjunto das classes trabalhadoras.

\subsection{O projeto de reestruturação da formação profissional}

Voltando à ESS/UCMG, no transcurso do final de 1968 a 1971 foram germinados os suportes propiciadores de um projeto acadêmico e profissional de feição crítica, sob a dinâmica contraditória da instauração do "terrorismo cultural sistemático" do regime autocrático, pelo "saneamento das universidades" e sua "refuncionalização" nos termos do 
acordo MEC-Usaid, como analisa Netto (1991 e 1982). Pesaram de forma decisiva nessa viragem os passos interativos, a partir dos encontros latino-americanos de Serviço Social, ${ }^{9}$ e além dos periódicos encontros e seminários, desbordou em um intenso intercâmbio intencionalmente buscado $^{10}$ entre o grupo mineiro e as vanguardas do movimento de reconceituação no continente, conforme depoimentos em Silva (1991). Também foram incorporados à escola áreas docentes - filosofia, história, jornalismo, sociologia e ciência política. No protagonismo da equipe, identifica-se a liderança de Leila Lima Santos, ex-integrante da JUC e dos quadros da Ação Popular, recém-chegada de uma pós-graduação em Sociologia do Trabalho na Universidade de Paris, onde, além de ter vivido o Maio de 1968 francês, cursou seminários com os marxistas Althusser e Lefebvre. Com o suporte dessa equipe inicia-se a revisão da formação, dos fundamentos do Serviço Social, com a formulação de um projeto no sentido de romper com o tradicionalismo no Serviço Social em suas implicações teórico-metodológicas e práticas, marcando uma inflexão na dinâmica de ensino da escola, da universidade católica e da profissão no país. Sustenta-se nesse estudo a reestruturação da formação profissional na escola de $\mathrm{BH}$ constitui um produto eminentemente universitário e nacional da reconceituação, portanto, sem as influências dos projetos das escolas dos demais países de língua hispânica, antes sofrendo inflexões de Paulo Freire e de inovações na universidade brasileira. Procura-se

9 Expressões da articulação político-profissional continental, amplamente impulsionada pelo Centro Latinoamericano de Trabajo Social (Celats ) e pela Associación Latinoamericana de Escuelas de Trabajo Social (Alaets), soldando uma unidade de diversidades nacionais. 0 primeiro encontro ocorreu em Porto Alegre em 1965, seguido pelos de Montevidéu, (Uruguai, 1966), Concepción (Chile, 1969), Cochabamba (Bolívia, 1970), e novamente em Porto Alegre (Brasil, 1972). (Iamamoto e Santos, 2016).

10 É importante assinalar o protagonismo de Ana Quiroga, nessa articulação a representação das revistas argentinas Ecro e Humanitas, divulgadoras da produção do Serviço Social latino-americano e de Consuelo Quiroga, vice-diretora da Escola de Serviço Social a partir de 1977, na criação em 1975 do Celats, órgão acadêmico da Alaets, com sede no Peru. Leila Lima, com o desfecho da proposta da ESS, assumiu a direção acadêmica do Centro, com linhas de pesquisas, criação do primeiro curso de mestrado do Serviço Social na América Latina e edição primorosa da Revista Acción Critica. 
também identificar que o projeto pedagógico implantado pela Escola de Serviço Social se tornou o núcleo originário das revisões da formação profissional desenvolvidas nas décadas de 1980 e 1990 conduzidas pela Abepss (2016).

A proposta alternativa formulada pela equipe docente da ESS/UCMG efetivou-se tanto no âmbito da elaboração teórica, da reestruturação curricular da formação, quanto da experimentação via projetos de extensão e campos de estágio. Esses são demonstrativos das suas preocupações teórico-práticas, operacionalizando com consistência, rigor, inteligência e coragem mecanismos institucionais da universidade e determinados espaços do exercício profissional. Podemos afirmar que tais mudanças implicaram ações em dois níveis. Primeiro, em uma reestruturação do ensino teórico-prático, sustentada na análise crítica da universidade brasileira. Buscou-se resgatar a possibilidade de condução da revisão curricular a partir da recuperação do relativo espaço de autonomia existente no âmbito decisório interno às unidades de ensino (ESS/UCMG,1971b). A concepção globalizadora da proposta de currículo sustentava-se na articulação do ensino teórico-prático à pesquisa, à docência e à prática, operacionalizado nas "unidades de ensino e aprendizagem" (UAs), concepção inédita na organização curricular da formação em Serviço Social do país. As UAs eram organizadas em projetos semestrais de aprendizagem (PSAs). Além disso, eram articuladas no "contato com a realidade" por meio de programas de investigação, programas de estudo, pesquisa e/ou ação profissional, realizados semestralmente, ao longo de oito semestres letivos, contemplando o conjunto de disciplinas e os respectivos conteúdos, inclusive as disciplinas especificamente profissionais.

As "equipes de prática" eram articuladas em torno de problemáticas básicas de investigação e intervenção profissional. Apoiavam-se em uma orientação interdisciplinar (com a incorporação dos docentes das áreas afins, em suas devidas áreas de atuação, participação de "monitoria" de discentes concluintes e de assistentes sociais supervisores de campo), resultando em possibilidade de avanços na relação entre formação teórica 
e exercício profissional, como demonstram os relatórios das "equipes de prática" e os trabalhos de conclusão, denominados Trabalhos de Estágio de Campo (Santos, 1985; Quiroga, 1973b).

No projeto da Escola de Serviço Social da UCMG, à semelhança de demais experiências da reconceituação latino-americana, também se registra a influência de Paulo Freire, mas que vai além de uma simples incorporação de suas ideias, avançando para uma ação mais radical, no plano da apreensão societária. Ela se expressa sobretudo na definição do objeto e objetivos da proposta metodológica contida nos documentos já referidos (Análise histórica da orientação metodológica da Escola de Serviço Social da UCMG, 1972, e A prática como fonte de teoria, 1971), baseados no pressuposto da exigência de uma análise da sociedade brasileira, que, no entanto, não se efetivou no projeto e se pôs como problemática na sua experimentação nos campos de estágio/extensão, particularmente nas cidades e bairros de predominância do operariado industrial dos anos 1970.

Considera que o objeto da atuação profissional é a "ação social da classe oprimida", incorrendo em um simplismo teórico com desdobramentos práticos para o exercício profissional. A noção de classe oprimida encobre as determinações da exploração inerente às relações sociais de produção capitalistas, e sendo principalmente uma noção política, sugere uma sociedade dicotômica, comprometendo o próprio potencial do vínculo profissional com os interesses do conjunto das classes trabalhadoras (como posteriormente o Serviço Social brasileiro assumiu). Esse objeto estava conectado ao objetivo meta, "a transformação da sociedade e do homem", através de objetivos meios, "a conscientização, a capacitação $e$ a organização". Tais definições trazem profundos equívocos e limitações, em que pesem o reconhecimento da tentativa de historicizar o objeto e os objetivos profissionais, o repúdio à neutralidade e ao transclassismo típicos do tradicionalismo profissional. Carregam as ilusões características de uma parcela da vanguarda profissional progressista naquele momento atualizando as marcas messiânicas, no trato dos profissionais, 
mediados pelos processos educativos da "pedagogia do oprimido", inspirados na perspectiva de Paulo Freire, decorrendo uma visão polarizadora da sociedade, dividida entre opressores e oprimidos.

Ainda que o projeto da ESS/UCMG seja expresso, em grande parte, no conhecido "Método de Belo Horizonte", analisado em Lima Santos (1985), Netto (1991), prioriza-se nesse artigo a explicitação dos vetores principais das concepções teórico-metodológicas que o norteiam nos caminhos de sua interlocução com a tradição marxista, eixo central da investigação.

\subsection{As aproximações aos "marxismos" nas formulações da Escola de BH}

A Escola de Serviço Social de Belo Horizonte talvez seja a única experiência da Reconceituação na qual se identifica a influência de Henrique Cláudio de Lima Vaz, pensador, filósofo e teólogo jesuíta, professor da Universidade Federal de Minas Gerais, estudioso da dialética hegeliana e do pensamento marxiano, assistente e mentor da JUC e atuante no MEB. Textos e livros dele, como Cristianismo e consciência histórica, de 1961, que exerceram considerável influência nos movimentos cristãos no Brasil (embora dissesse que "eram textos de reflexão, não de ação") foram referências bibliográficas nos documentos elaborados pela equipe docente da ESS/UCMG. A influência desse "marxismo" na proposta da Escola de Serviço Social de BH se efetiva pelo protagonismo de docentes (não só assistentes sociais, mas também de outras áreas disciplinares, como filósofos e economistas) e discentes que tiveram atuação na esquerda católica. Destaca-se, mais uma vez, Leila Lima, que em vários depoimentos concedidos assinala os caminhos de sua aproximação ao marxismo pela via do "humanismo cristão", tendo recebido formação e orientação diretamente de "cursos" com o padre Vaz, desde 1961, como dirigente da JUC em Minas Gerais e já estudante de Serviço Social na Universidade Católica. 
Os conturbados e efervescentes anos 1960 na vida brasileira fizeram com que o padre Vaz compreendesse "as urgências da política e impuseram-lhe a tarefa de uma leitura crítica e cristã do pensamento marxiano", introduzindo novos posicionamentos e rumos à juventude católica que deveria "dar testemunho da fé na própria militância política”, como assinalam depoimento do filósofo (Nobre; Rego, 2000, p. 29-44).

Löwy aponta uma característica original do catolicismo brasileiro, que, combinada ao quadro societário, possibilitou o surgimento das primeiras formulações de um pensamento cristão com recorrências ao marxismo. Para o autor, existia na Igreja católica brasileira um ambiente cultural mais receptivo às novas ideias radicais do que em outros lugares da América Latina, dada a influência da cultura católica francesa.

A França é o país onde, ao longo do século XX, pôde-se ver as evoluções mais radicais da cultura cristã (em particular, da católica): o socialismo religioso de Charles Péguy e Emmanuel Mounier e o seu grupo em torno da revista Esprit, os socialistas cristãos da Frente Popular; os cristãos antifascistas da resistência (Témoignane Chrétien), a nova teologia do pós-guerra (Calvez, Chénu, Duquoq, Lubac etc.), a economia humanista do Pe. Lebret, os padres-operários, a virada à esquerda da Juventude Católica (JUC, JEC) e os sindicatos católicos (a CFTC) durante os anos de 1950 e 1960. (Lowy, 1991, p. 59)

A formulação de um "socialismo humanista" na JUC foi resgatado, em parte, pela Ação Popular (AP), organização partidária originária do agrupamento católico, cuja militância teve forte presença entre professores e estudantes da Escola de Serviço Social. Nessa "passagem" identifica-se igualmente a influência do padre Vaz, divulgador da Revue d'Action Populaire, publicada pelos jesuítas franceses, que deu origem ao nome Ação Popular à organização. A linha humanista foi, no âmbito internacional, desde meados dos anos 1950, exaltada como o elo comum que unia aliados no plano prático: comunistas, socialistas e católicos (Lowy, 1991; Silva, 1991). 
Também Lowy e sua análise sobre o marxismo na América Latina oferecem uma chave analítica para situar as influências teóricas na Escola Mineira no estágio de apropriação e difusão do pensamento de Marx e da tradição marxista à época.

Como já bem analisada pela literatura de balanço crítico da Reconceituação, inclusive a experiência da Escola de Serviço Social de Minas Gerais (Netto, 1992; Iamamoto, 1998; Quiroga, 1989), essa aproximação dos docentes e discentes com a tradição marxista operou-se pela via política, com uma instrumentalização que legitima as estratégias e táticas transportadas para a esfera profissional.

A pesquisa e a análise documental permitem-nos sugerir que a influência das ideias de Althusser na proposta belo-horizontina teria dois vetores que se conectam nas suas formulações teórico-metodológicas. Primeiro, a formação da docente Leila Lima, como já apontado. O outro vetor encontra-se na influência de Althusser nas propostas e experiências da reconceituação nos países de língua hispânica, especialmente as formulações desenvolvidas nas universidades chilenas, com as quais a equipe docente estabeleceu vínculos e articulações. As ideias althusserianas se afirmaram por essa via pelo recurso a teses de sua discípula Marta Harnecker. As ideias de Althusser são identificadas na produção documental da Escola de Belo Horizonte através das tematizações sobre "ideologia”, "ciência”, "teoria”, "prática”, "prática teórica”, apreendidas dos livros A favor de Marx e Sobre o trabalho teórico: dificuldades e recurso (são citados em francês e/ou espanhol).

Quanto à recorrência à concepção maoísta, ela é igualmente recolhida dos ensaios Sobre a prática e Sobre a contradição, também acessados pela via política da militância, ainda que essa aproximação fosse explicitada como busca de uma base científica e teórica para o projeto. A análise detalhada da proposta metodológica da Escola de BH contida nos documentos formulados no período de 1971 a 1975 Análise histórica da orientação metodológica da Escola de Serviço Social da Universidade Católica de Minas Gerais (1972) e A prática como fonte 
de teoria (1971a) - oferece as chaves para apreender os extratos do maoísmo demarcando o forte traço empiricista que caracteriza esse viés da tradição marxista, aqui compondo com o reducionismo presente no epistemologismo de raiz estruturalista e da vulgarização marxista. O maoismo contido na proposta metodológica se evidencia no "marco referencial teórico" que fundamenta a estruturação do conhecido "Método $\mathrm{BH}$ ", no qual o processo de conhecimento da realidade se dá pela sucessão de "momentos sensíveis e abstratos", até alcançar o conhecimento científico, "racional". A discussão da relação entre teoria e prática é inteiramente compreendida pela determinação de que "a prática é produtora de conhecimentos" (em Mao a posição é: "todo conhecimento autêntico nasce da experiência direta"), ainda que na argumentação o texto explicite a necessidade de romper com o empirismo como marca do tradicionalismo profissional. A relação entre teoria e prática é apresentada por caminhos recolhidos de manuais - "interdependência", "simultaneidade", "circularidade”, "transformação mútua”, "contraditoriedade" - enfeixada pelas "leis da dialética”, explicitadas do mesmo modo. Essas concepções e cultura são amplamente difundidas no meio profissional latino-americano, tendo ocorrido inclusive um importante evento continental sobre o tema - A prática como fonte de teoria em Ambato, Equador, em 1971.

Mas, ainda na formulação do "marco referencial teórico", a proposta parte da teoria do conhecimento inspirada em teses da teoria do reflexo de Lenin em texto de 1906, Materialismo e empiriocriticismo, obra de grande questionamento na tradição marxista pelo dogmatismo e sua referência no marxismo-leninismo veiculado pela II Internacional.

Ao mesmo tempo, encontra-se na proposta a introdução de interpretações sobre a prática recolhidas de Adolfo Sanchez Vásquez em sua Filosofia da práxis, autor que se situa noutra chave analítica do marxismo e que elaborou uma das críticas que contribui para desmontar os equívocos de Althusser em Ciência e revolução - o marxismo de Althusser. No entanto, na formulação de $\mathrm{BH}$, o aporte de Vásquez não alcançou 
desdobramentos problematizadores e críticos naquele momento na formulação de escola mineira.

A natureza da aproximação incipiente na tradição marxista impregna a proposta da Escola de Serviço Social da UCMG de um lastro eclético, percorrendo todas as suas formulações, expressas no empirismo constituinte da estruturação do "Método BH", orientadas por uma reflexão sustentada no epistemologismo que indica a invasão positivista do marxismo, como analisa Quiroga (1989). Esses substratos acabaram por não possibilitar a iluminação teórica que era pretendida, pois só chancelaram os equívocos próprios da instrumentalização eivada da via política da militância.

Coutinho (2010, p. 175-194) oferece chaves para a análise crítica dessa aproximação eclética e epistemologista, entre outras, ao enfatizar a compatibilidade dogmática entre Althusser - a quem se deve a contribuição ao conceito de prática teórica - e as posições filosóficas empíricas de Mao Tsé-tung (e Stálin), demarcando o anti-humanismo althusseriano com o "corte epistemológico" e a eliminação da ontologia dialética de Marx. Como registra Netto (1992, p. 287), as debilidades e equívocos dessa proposta se devem às limitações do viés da tradição marxista que ela incorpora:

O "marxismo sem Marx" [...] precisamente à falta de uma sustentação ontológico-dialética e na escala em que deveria conectar teoria e intervenção prático-profissional, vai na direção da conjugação do fatalismos mecanicista com o voluntarismo idealista - numa "síntese" que, como Lukács o demonstrou há muito, é típica do marxismo vulgar necessariamente eclético.

Entende-se que um elemento decisivo nesse ecletismo teórico deve-se às dificuldades e impedimentos de acesso às fontes, impostos pela censura do regime ditatorial. Lembre-se que toda literatura, livros e documentos, inclusive de Paulo Freire, eram "importados" clandestinamente. Assim demarca-se que a interpretação aqui se assenta de forma privilegiada nos constrangimentos históricos e conjunturais, não recaindo sobre lacunas e equívocos dos sujeitos. 


\section{Considerações finais}

Resta ainda alertar que a interrupção em 1975 de toda a proposta renovadora na intenção de ruptura da Escola de Belo Horizonte, não tratada nos limites deste artigo, impediu que sua equipe docente e discente avançasse na própria experiência, na continuidade, na superação dos equívocos e limitações, no processo de crítica e autocrítica da aproximação ao marxismo e dos desdobramentos formulados no âmbito da profissão (fundamentos, formação e exercício profissional) imediatamente naquele período. Mas é necessário registrar que esses avanços e superação se deram inclusive por parte de suas principais formuladoras, seja no balanço da proposta de $\mathrm{BH}$, de Leila Lima, no já clássico texto "Metodologismo: estallido de una época" (1977), em coautoria com o colombiano Roberto Rodriguez, seja em seu central protagonismo no Celats de 1977 a 1983, seja também na pesquisa de Consuelo Quiroga (1989) publicada no importante ensaio Uma invasão às ocultas: reduções positivistas no marxismo e suas manifestações no ensino de Serviço Social. As duas publicações ultrapassam uma avaliação da proposta da Escola de Serviço Social mineira, pois contêm chaves para tratar dos traços e processos que marcaram o conjunto das elaborações da reconceituação latino-americana.

No entanto, foi com a produção teórica de Marilda Villela Iamamoto, também docente e uma das formuladoras de $\mathrm{BH}$, uma década mais tarde (1982), cuja pesquisa e reflexão é em parte publicada no clássico Relações sociais e Serviço Social no Brasil - em coautoria com Raul de Carvalho - , que se efetivou o marco de uma inflexão na apropriação do referencial próprio do legado de Marx. Inscrevendo a profissão imbricada na lógica da produção e reprodução das relações sociais, inaugurou no Serviço Social latino-americano as chaves para superação dos empirismos e (neo)positivismos que caracterizaram o primeiro momento da reconceituação no Brasil, tal como expresso no projeto da Escola de Serviço Social de Minas Gerais. 
Deve-se ressaltar que a análise crítica do projeto acadêmico e profissional da escola mineira orientava-se pela afirmação da importância teórica e ideológica de sua aproximação à tradição marxista, realizada sob adversas condições políticas da sociedade e da universidade brasileiras sob a ditadura empresarial militar de 1964. A proposta abrangente e qualificada como uma alternativa global ao tradicionalismo é demonstrativa das suas preocupações teórico-práticas, da consistência, rigor e congruência nos planos teórico-metodológicos, dos fundamentos da formação e do exercício profissional. Passados quase cinquenta anos da experiência da ESS/UCMG, com o distanciamento temporal, é possível apreender sua relevância na história recente do Serviço Social no país, inscrito nas particularidades da formação social brasileira, referida aos processos de constituição e crise da ditadura empresarial militar, das lutas sociais das classes subalternas, solo privilegiado para decifrá-la. $\mathrm{E}$, ao mesmo tempo, develar os substratos ideoculturais, as teorias e interpretações prevalecentes formuladas e incorporadas que incidiram nas suas formulações. E esse segue como um dos caminhos para desvelar as exigências teóricas e práticas postas ao Serviço Social no presente.

\section{Referências}

ALAYÓN, N. (Org.). Trabajo social latino-americano: a 40 años de la reconceptualización. Buenos Aires: Espacio Ed., 2005.

BARBOSA, M. M. Objetivos profissionais e objetivos institucionais na trajetória do Serviço Social: Belo Horizonte 1960-1984. Tese de Doutorado — PUC-SP, São Paulo, 1989.

CFESS - Conselho Federal de Serviço Social. Serviço Social, memórias e resistências contra a ditadura: depoimentos. Brasília: CFESS, 2017.

COMISSÃO DA VERDADE EM MINAS 1964/1988. Relatório final. Belo Horizonte, 2017. v. 5. COUTINHO, C. N. O estruturalismo e a miséria da razão. 2. ed. São Paulo: Expressão Popular, 2010.

ESS/UCMG — Escola de Serviço Social da Universidade Católica de Minas Gerais. A prática como fonte de teoria. Belo Horizonte: ESS/UCMG, 1971a. Mimeografado.

. Análise histórica da orientação metodológica da Escola de Serviço Social da UCMG. Belo Horizonte: ESS/UCMG, Minas Gerais, 1974. Mimeografado. 
ESS/UCMG — Escola de Serviço Social da Universidade Católica de Minas Gerais. Uma proposta de reestruturação da formação profissional. Belo Horizonte: ESS/UCMG, 1971c. Mimeografado.

FERNANDES, E. (Org.). Massacre de Ipatinga. Brasília: Ministério da Justiça, Comissão de Anistia, 2013.

FERNANDES, F. A revolução burguesa no Brasil. Rio de Janeiro: Zahar, 1976.

A universidade brasileira: reforma ou revolução? São Paulo: Alfa Ômega, 1979.

GÓES, M.; CUNHA, L. A. O golpe na educação. Rio de Janeiro: Zahar, 1985.

IAMAMOTO, M. V. O debate contemporâneo da reconceituação do Serviço Social: ampliação e aprofundamento do marxismo. In: IAMAMOTO, M. V. Serviço Social na contemporaneidade: trabalho e formação profissional. São Paulo: Cortez, 1998. p. 201-250.

; CARVALHO, R. Relações Sociais e Serviço Social no Brasil. São Paulo: Cortez, 1982.

; SANTOS, C. M. (Coords.). O Movimento de Reconceituação do Serviço Social na América Latina (Brasil, Chile, Argentina e Colômbia): determinantes históricos, interlocuções internacionais e memória. Projeto de Pesquisa/Uerj: Rio de Janeiro, fev. 2016. Mimeografado.

IANNI, O. A ditadura do grande capital. Rio de Janeiro: Civilização Brasileira, 1981.

LIMA, L.; RODRIGUEZ, R. Metodologismo: estallido de una época. Acción Critica, Lima (Peru), n. 2, p. 15-41, jul. 1977.

LIMA SANTOS, L. Textos de Serviço Social. São Paulo: Cortez, 1982.

LOWY, M. Marxismo e teologia da libertação. São Paulo: Cortez, 1991.

MOTTA, R. P. S. As universidades e o regime militar: cultura política brasileira e modernização autoritária. Rio de Janeiro: Zahar, 2014.

NETTO, J. P. A crítica conservadora à reconceptualização. Serviço Social \& Sociedade, São Paulo, n. 5, p. 59-75, 1981. . Ditadura e Serviço Social. São Paulo: Cortez, 1991. . Pequena história da ditadura brasileira (1964-1985). São Paulo: Cortez, 2014.

NEVES, M. de A. Trabalho e cidadania: as trabalhadoras de Contagem. Rio de Janeiro: Vozes, 1995.

QUIROGA, C. (Org.). Compendio sobre metodología para el trabajo social. Buenos Aires: Editorial Ecro, 1973a. (Série ISI 4).

. Compendio sobre reestructuración de la carrera de trabajo social. Buenos Aires: Editorial Ecro, 1973b. (Série ISI 5).

Uma invasão às ocultas: reduções positivistas no marxismo e suas manifestações no ensino de Serviço Social. São Paulo: Cortez, 1989. 
SILVA, L. M. R. Aproximação do Serviço Social à tradição marxista: caminhos e descaminhos. Tese de Doutorado. Programa de Estudos Pós-Graduados em Serviço Social — PUC/SP, São Paulo, 1991. v. 1 e 2.

STARLING, H. M. M. Os senhores das Gerais: os novos inconfidentes e o golpe militar. Petrópolis: Vozes, 1986.

VÁSQUEZ. A. S. Ciência e revolução: o marxismo de Althusser. Rio de Janeiro: Civilização Brasileira, 1980. Filosofia da práxis. 2. ed. São Paulo: Expressão Popular, 2011.

VAZ, H. C. L. Um depoimento. In: NOBRE, M.; REGO, J. M. Conversas com filósofos brasileiros. São Paulo: Editora 34, 2005. 1963. Cristianismo e consciência histórica. Síntese - Revista de Filosofia. São Paulo,

\section{Sobre a autora}

Maria Rosângela Batistoni - Doutora em Serviço Social pela Pontifícia Universidade Católica de São Paulo, professora do curso de Serviço Social e do Programa de Pós-Graduação Serviço Social e Políticas Sociais da Universidade Federal de São Paulo.

E-mail: rosangelabatistoni@gmail.com 